

\title{
Papel das Universidades no Sistema Nacional de Inovação
}

\section{Daniel P. B. Queiroz ${ }^{*}$ Renato de Castro Garcia}

\section{Resumo}

O objetivo do projeto é analisar o papel das universidades no sistema nacional de inovação. O estudo pretende mostrar a importância das universidades para o sistema nacional de inovação, principalmente para o caso brasileiro. A relação entre as universidades e as empresas representam um fator importante, por isso que foram analisadas as características dessa relação a partir da análise de bancos de dados e literaturas. Os principais resultados envolvem a compreensão da vital contribuição das universidades para o sistema nacional de inovação e como essa contribuição afeta o desenvolvimento tecnológico e científico de um país e das empresas.

\section{Palavras-chave:}

Sistema Nacional de Inovação, Universidades, Inovação.

\section{Introdução}

O objetivo geral deste trabalho é entender o papel das universidades no sistema nacional de inovação. Para ser atingido esse objetivo foi feita uma pesquisa das características das relações entre empresas e universidades, através de pesquisa no banco de dados Diretório dos Grupos de Pesquisa de Lattes do CNPq.

A escolha do tema foi feita a partir da necessidade de tentar entender o papel das universidades na economia e da nossa sociedade. Uma das principais características do desenvolvimento capitalista atual é o incremento do conteúdo técnico das tecnologias. Para países como o Brasil, há muito o que adquirir ainda, e, portanto, as interações entre universidades e empresas são mais importantes.

\section{Resultados e Discussão}

Para realizar a proposta desse projeto de iniciação científica, o estudo foi divido em duas etapas.

Em primeiro lugar, foi realizado uma revisão e levantamento bibliográfico mais amplo sobre o tema de financiamento à inovação no Brasil. Em seguida, foi realizado um levantamento da importância da universidade dentro do sistema nacional de inovação do Brasil, por meio da coleta e da organização dos dados do Censo de 2014 e 2015 do Diretório dos Grupos de Pesquisa da base Lattes do CNPq. Isso permitiu que fosse realizado um mapeamento do papel exercido pelos grupos de pesquisa universitários na transferência de conhecimentos e de novas tecnologias às empresas no Brasil.

A segunda etapa foi constituída pela análise dos padrões de colaboração entre universidades e empresas no Brasil. Com a base de dados coletada e organizada, foi possível realizar uma análise mais abrangente das características dos projetos de colaboração entre as universidades e as empresas no Brasil, o que envolveu características segundo os fatores como: áreas do conhecimento, setores da atividade econômica, distribuição regional, forma de colaboração, tipo de financiamento, entre outras variáveis.
Vale apontar que este projeto se insere em um esforço mais geral, e coletivo, de pesquisa sobre o tema geral "Economia da Inovação", que envolve outros pesquisadores da Unicamp e de outras universidades. No âmbito desses projetos, diversos resultados já alcançados podem ser destacados, como a publicação de diversos artigos periódicos brasileiros e internacionais com política seletiva de publicação, capítulos de livros, a apresentação de artigos do Congresso da ANPEC e trabalhos em eventos no Brasil e no exterior.

\section{Conclusões}

O Brasil se encontra em um estágio ainda imaturo da construção de seu Sistema Nacional de Inovação. Uma das características marcantes do sistema de inovação brasileiro que difere dos países desenvolvidos é a existência de instituições de pesquisa e ensino montadas, mas que ainda não conseguem mobilizar seus pesquisadores, cientistas e técnicos nas mesmas proporções que esses países. Vale a pena destacar também que, no caso brasileiro, as empresas ainda apresentam um fraco envolvimento das atividades inovativas, ou seja, não existe uma interação forte entre empresas e universidades.

Existe uma diversidade de interações universidadeempresa que depende inúmeros fatores e que essas interações ocorrem através de diversos meios, e que por causa disso, são necessárias boas políticas públicas que levem essa diversidade em questão.

\section{Agradecimentos}

Agradeço a orientação do Prof. Dr. Renato Garcia (IEUnicamp) e o apoio dado pelo CNPq/PIBIC através do programa de Iniciação Científica. 